\title{
Stent technology in ischemic stroke
}

\author{
Nam K. Yoon, MD, AI-Wala Awad, MD, M. Yashar S. Kalani, MD, PhD, Philipp Taussky, MD, and \\ Min S. Park, MD
}

Department of Neurosurgery, Clinical Neurosciences Center, University of Utah, Salt Lake City, Utah

\begin{abstract}
Atherosclerotic disease of the cerebral vasculature is a major cause of stroke worldwide. Atherosclerosis that is refractory to best medical management may require revascularization. In these instances, endovascular treatment provides a popular and safe alternative to open surgical techniques. The authors provide an overview of stent technology in the treatment of ischemic stroke, discussing the major studies evaluating stenting for extracranial carotid artery, vertebral artery, and intracranial atherosclerotic disease. The authors describe the commonly used stents with respect to their individual characteristics and technical limitations. Current and future developments in stent technology are also discussed, with areas for further innovation and clinical research.
\end{abstract}

https://thejns.org/doi/abs/10.3171/2017.1.FOCUS16507

KEY WORDS atherosclerotic disease; stent; ischemic stroke; carotid endarterectomy

$\mathrm{E}$ ACH year, approximately 800,000 people in the US will experience a new or recurrent stroke, of which $87 \%$ are ischemic in nature. ${ }^{47} \mathrm{~A}$ large proportion of these strokes are secondary to vascular atherosclerotic disease, some of which can be refractory to best medical management. To treat atherosclerotic disease, endovascular revascularization with the use of stents has gained increasing popularity and acceptance as a safe and less-invasive alternative to open surgical revascularization procedures. In this review, we discuss studies that have attempted to validate the use of various stents for different indications, as well as the individual devices themselves with their specific characteristics. Finally, because stent technology is constantly evolving, current areas of research and development, and pharmacological strategies for minimizing stent restenosis are discussed.

\section{Review of Current Stents \\ Extracranial Carotid Artery Stents}

Atherosclerotic disease of the extracranial carotid artery accounts for approximately $30 \%$ of all ischemic strokes. Level 1 evidence from the North American Symptomatic Carotid Endarterectomy Trial (NASCET) demonstrates that carotid endarterectomy (CEA) decreases the risk of stroke in patients with severe stenosis, although this technique carries the typical risks of open surgery. ${ }^{51}$ Since the 1980s, endovascular techniques and devices have been developed as an alternative to CEA (Fig. 1), and multiple prospective randomized trials have evaluated their individual safety and efficacy.

The Carotid and Vertebral Artery Transluminal Angioplasty Study (CAVATAS) compared angioplasty, angioplasty plus stenting, and CEA and showed that while minor strokes that lasted less than 7 days were more common in the endovascular group (3.2\% vs $0.4 \%)$, the number of other strokes in any territory or deaths was the same. ${ }^{26}$ Carotid artery stenting (CAS) was used in only $26 \%$ of the endovascular treatment group, but its use resulted in a significantly lower incidence of restenosis. The Stenting and Angioplasty with Protection in Patients at High Risk for Endarterectomy (SAPPHIRE) trial randomized highrisk surgical patients (significant cardiac disease, recurrent stenosis, and age $>80$ years) to either CAS with mandatory embolic protection devices or CEA, and found that the CAS group had a lower major adverse event rate at 30 days $(4.8 \%$ vs $9.8 \%)$ and 1 year $(12.2 \%$ vs. $20.1 \%){ }^{69}$ Highrisk patients were excluded in the International Carotid Stenting Study (ICSS), which showed no difference in the number of fatal or disabling strokes or in the modified

ABBREVIATIONS BMS = bare-metal stent; BVS = bioresorbable vascular scaffold; CAS = carotid artery stenting; CAVATAS = Carotid and Vertebral Artery Transluminal Angioplasty Study; CCA = common carotid artery; CE = Confirmité Européene; CEA = carotid endarterectomy; DEB = drug-eluting balloon; DES = drug-eluting stent; ISR = in-stent restenosis; PED = Pipeline Embolization Device; SAMMPRIS = Stenting and Aggressive Medical Therapy for Preventing Recurrent Stroke in Intracranial Stenosis; TZD = thiazolidinedione; VAS = vertebral artery stenosis; WASID = Warfarin-Aspirin Symptomatic Intracranial Disease.

SUBMITTED November 30, 2016. ACCEPTED January 23, 2017.

INCLUDE WHEN CITING DOI: 10.3171/2017.1.FOCUS16507. 

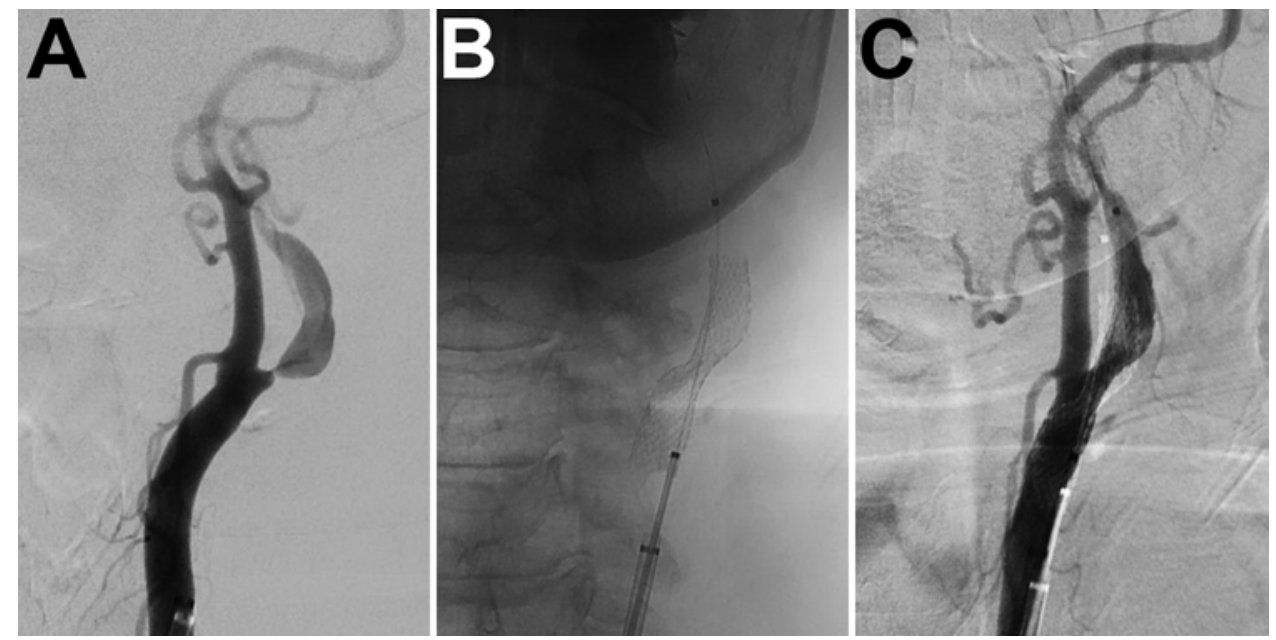

FIG. 1. A: Digital subtraction angiography (DSA) showing severe narrowing of the left internal carotid artery at the carotid bulb in a 63-year-old woman. B: A $7 \times 30-$ mm Precise carotid stent was deployed over the area of stenosis. C: Follow-up angiogram showing significant improvement in vessel caliber.

Rankin scale scores at 1- and 5-year follow-up. ${ }^{8}$ Patients in the CAS group did have a higher risk of nondisabling strokes than those in the CEA group (15.2\% vs $9.4 \%)$.

The largest randomized controlled trial (2502 patients), the Carotid Revascularization Endarterectomy versus Stenting Trial (CREST), demonstrated CAS can be as effective as CEA for preventing strokes in both symptomatic and asymptomatic patients with carotid artery stenosis (7.2\% vs 6.8\% 4-year risk of stroke, myocardial infarction, or death). ${ }^{11}$ The protocol specified the use of the RX Acculink stent (Abbott Vascular) as well as the RX Accunet embolic protection device whenever feasible in the CAS group. There was a higher risk of periprocedural stroke in the stenting group ( $4.1 \%$ vs $2.3 \%$ ) but a higher risk of myocardial infarction in the endarterectomy group $(1.1 \%$ vs $2.3 \%$ ). As a result of these studies, the Centers for Medicare and Medicaid Services currently recommends CAS with embolic protection devices in patients at high risk for CEA, defined by factors such as significant cardiac comorbidities, contralateral carotid occlusion, previous CEA with recurrent stenosis, and prior neck radiation.

Stents used for CAS are self-expanding stents that can be closed cell or open cell, have a straight or tapered design, and are made of various metallic materials. The common CAS devices are listed in Table 1, with these factors described. The self-expanding nature allows the stent to expand against the plaque and exert an outward radial force that resists compression. The force depends on the stent design, as well as size of the stent chosen compared with the final vessel caliber (oversizing a stent). Open-cell stents tend to have greater radial force because their cells can freely open; however, excessive radial force can cause stent impaction and plaque protrusion.

Closed-cell stents have regularly spaced open spaces (cells) that are completely separated from other cells by tines, whereas open-cell stents are connected to other cells through incomplete tines. This allows closed-cell stents to have smaller cell areas that provide better wall coverage but tend to be more rigid and conform less to more tortuous vessels. Open-cell stents can have struts extending into the lumen that can sometimes interfere with passage of catheters for use of embolic protection devices. Hybrid stents have also been developed to take advantage of the benefits of each type in separate segments, depending on the morphology of the vessel and lesion.

Tapered designs can be useful when deploying stents across the carotid bifurcation, as the common carotid artery (CCA) is typically larger than the internal carotid artery. The tapered design means that the maximum diameter at the proximal end is larger than that of the distal end, better matching the caliber of the CCA. Tapered stents can have a gradual, conical taper or a more abrupt, shouldered taper. Currently used stents are bare-metal stents (BMSs) commonly constructed of nitinol, a metal alloy of nickel and titanium. The Wallstent (Boston Scientific), which was initially approved for biliary use, is constructed of Elgiloy, a metal alloy of cobalt, chromium, iron, nickel, molybdenum, and manganese.

\section{Vertebral Artery Stents}

Posterior circulation strokes account for approximately $20 \%$ of all ischemic strokes, with approximately $9 \%-20 \%$ of these caused by vertebral artery stenosis (VAS). ${ }^{9} \mathrm{Al}-$ though the natural history of VAS is not well understood, posterior circulation strokes carry a high rate of morbidity

TABLE 1. Stents used to treat carotid artery stenosis

\begin{tabular}{llcccl}
\hline Stent & \multicolumn{1}{c}{ Manufacturer } & Material & $\begin{array}{c}\text { Cell } \\
\text { Type }\end{array}$ & $\begin{array}{r}\text { Cell } \\
\text { Area } \\
\left(\mathrm{mm}^{2}\right)\end{array}$ & $\begin{array}{c}\text { Straight } \\
\text { vs } \\
\text { Tapered }\end{array}$ \\
\hline Wallstent & Boston Scientific & Elgiloy & Closed & 1.08 & Straight \\
\hline Xact & Abbott Laboratories & Nitinol & Closed & 2.74 & Both \\
\hline NexStent & Boston Scientific & Nitinol & Closed & 4.70 & Tapered \\
\hline Precise & Cordis Endovascular & Nitinol & Open & 5.89 & Straight \\
\hline Protégé & ev3 & Nitinol & Open & 10.71 & Both \\
\hline Acculink & Abbott Vascular & Nitinol & Open & 11.48 & Both \\
\hline
\end{tabular}


and mortality. ${ }^{46}$ Prospective randomized trials investigating best medical management of VAS are lacking, and patients with symptomatic disease are commonly treated with antiplatelet therapy and risk factor management. $\mathrm{Pa}-$ tients who continue to have symptoms are considered eligible for either surgical or endovascular intervention for revascularization of the vertebral artery. Given the technical difficulty and morbidity of open revascularization procedures such as primary endarterectomy or transposition of the vertebral artery, endovascular intervention has become the preferred treatment modality in many centers (Fig. 2).

The CAVATAS trial failed to demonstrate any benefit of endovascular intervention with balloon angioplasty and stenting over best medical management; ${ }^{19}$ however, the study was underpowered with only 8 patients in each treatment arm and no posterior circulation strokes in either arm. Further prospective multicenter trials have also failed to demonstrate benefit of stenting over medical therapy. The Vertebral Artery Stenting Trial (VAST) was terminated early after enrolling 115 patients because funding was cut after new regulatory requirements were introduced. ${ }^{17}$ Although not adequately powered, it failed to demonstrate superiority of stenting over best medical therapy in symptomatic patients with at least $50 \%$ stenosis. The Vertebral Artery Ischemic Stenting Trial (VIST) suffered the same fate, with withdrawal of funding midway through enrollment. Results presented at the European Stroke Organization Conference in 2016 indicated a trend toward fewer strokes in the stenting group versus the medical group (hazard ratio $0.40,95 \%$ confidence interval $0.14-1.13$; $p$ $=0.08){ }^{33}$

Currently, no stents have been approved by the US FDA specifically for the treatment of VAS. Coronary artery stents are commonly used off-label for this purpose. The first prospective multicenter study, the Stenting of Symptomatic Atherosclerotic Lesions in the Vertebral or Intracranial Arteries (SSYLVIA) trial, found that $44.4 \%$ of the 18 patients who underwent stenting with BMS for symptomatic atherosclerotic lesions in the extracranial vertebral artery developed in-stent restenosis (ISR) of $>50 \%$. This is likely because the vertebral artery origin has a well-developed muscularis layer, much like other ostial segments such as coronary arteries. As a result of this finding, drugeluting stents (DESs) were then co-opted from the cardiac world.

Early, first-generation coronary DESs were designed to release sirolimus (Cypher, Cordis Corp.) or paclitaxel (Taxus, Boston Scientific) and were found to decrease the rate of ISR in coronary arteries, ${ }^{55,59}$ likely by limiting macrophage accumulation and smooth muscle cell proliferation around the stent. ${ }^{66}$ Since then, these DESs have been used off-label for VAS, with several studies comparing DESs and BMSs with regard to ISR. A large metaanalysis of 5 studies demonstrated a significantly lower ISR rate in the DES group than in the BMS group when used to treat atherosclerotic disease of the extracranial vertebral artery $(15.49 \%$ vs $33.57 \%$, odds ratio $0.388, p=$ $0.001)$ and a lower rate of recurrent symptoms $(2.76 \%$ vs $11.26 \%$, odds ratio $0.301, \mathrm{p}=0.001) .{ }^{65}$ One limitation of this study, however, was the relatively short follow-up du-
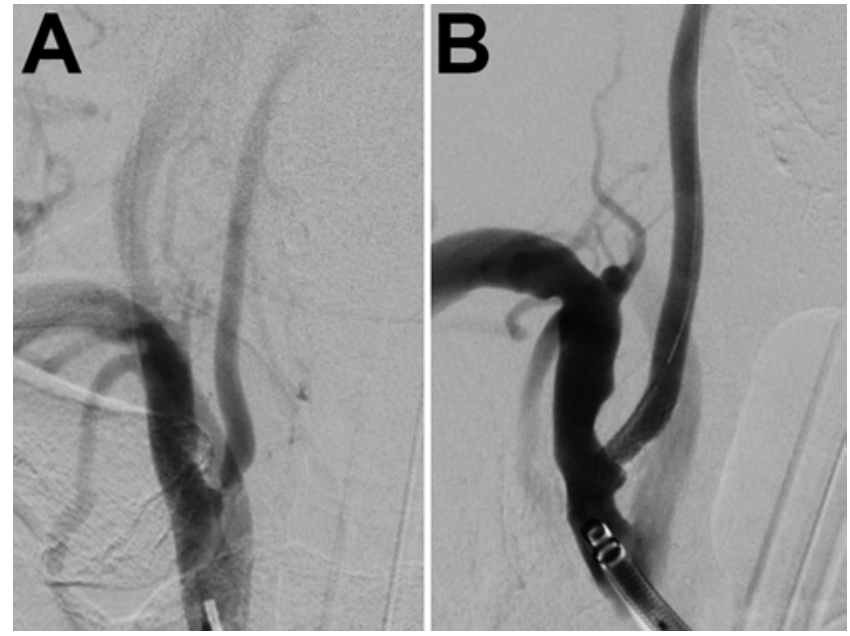

FIG. 2. Images obtained in a 76-year-old woman who experienced a contralateral vertebral artery injury that required endovascular occlusion. A: DSA showing severe symptomatic stenosis originating from the right vertebral artery. B: A $3 \times 12-m m$ Resolute Integrity RX coronary stent was deployed over the area of stenosis, with follow-up angiography showing significant improvement in the area of severe stenosis.

rations - as short as a mean of 14.2 months of radiological follow-up in the DES group - which precluded the ability to evaluate for late ISR.

In the coronary literature, late and very late in-stent thrombosis is a common problem, ${ }^{27}$ with the eluted drug inhibiting complete endothelialization of the stent struts. This causes increased long-term thrombogenicity of the stent, requiring prolonged antiplatelet use. As a response to these findings, second-generation coronary DESs have been developed with better vascular compatibility and less thrombogenicity. Xience V (Abbott Vascular), an everolimus-eluting stent, and Endeavor (Medtronic Vascular), a zotarolimus-eluting stent, have been found to have a lower risk of late in-stent thrombosis compared with earlier devices. ${ }^{2}$ There are currently no studies investigating these newer stents and their rate of late ISR or thrombosis in the vertebral artery.

Studies evaluating the natural history of vertebral artery atherosclerotic disease are lacking, as are robust prospective randomized trials comparing stenting versus best medical therapy. Although there is some evidence from retrospective nonrandomized studies that DESs may be superior to BMSs in preventing ISR during the short term, little is known about their long-term performance. What has been demonstrated through various studies is that vertebral artery stenting has a low rate of periprocedural complications. ${ }^{65}$ Given the neurological impact of posterior circulation strokes, endovascular treatment is likely to be warranted in a select group of patients, although further prospective randomized studies are clearly needed.

\section{Intracranial Stents}

Acute ischemic infarction from intracranial atherosclerotic disease accounts for approximately 8\%-10\% of strokes in the US each year. ${ }^{58}$ The Warfarin-Aspirin Symptomatic Intracranial Disease (WASID) trial demonstrated that the recurrent stroke risk of a patient with se- 

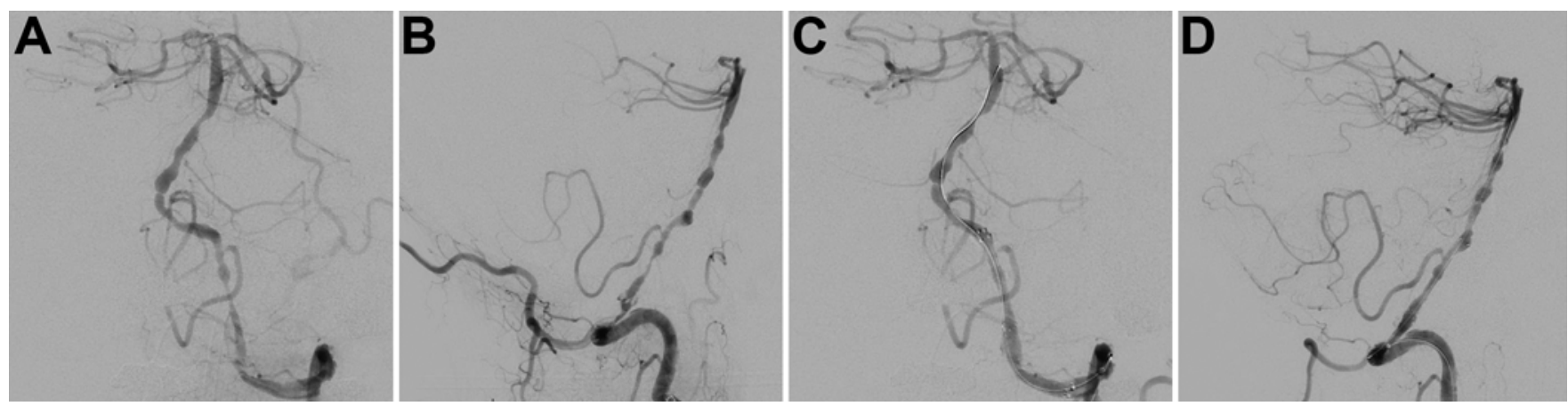

FIG. 3. Angiograms from a 63-year-old man with severe atherosclerotic disease of the intracranial vertebral and basilar arteries. A and B: Transfacial (A) and lateral (B) DSA projections. C and D: Two $4 \times 20-\mathrm{mm}$ Wingspan stents were deployed, and follow-up angiography demonstrated improvement in vessel caliber.

vere symptomatic intracranial stenosis $(70 \%-99 \%)$ was as high as $23 \%$ in 1 year despite best medical therapy at the time with either aspirin or warfarin,${ }^{16}$ and subsequent trials have supported the use of dual antiplatelet therapy for improved treatment of arterial stenosis. ${ }^{43}$ The poor natural history of symptomatic high-grade stenotic lesions despite best medical therapy logically presented an opportunity for endovascular intervention with balloon angioplasty and stenting to improve the caliber of the stenotic segment and perhaps improve patient outcomes (Fig. 3).

The Wingspan Stent System (Stryker Neurovascular) with the Gateway PTA Balloon Catheter is currently the only FDA-approved intracranial stent device under $\mathrm{Hu}-$ manitarian Device Exemption. The Wingspan stent is a 3.5-Fr nitinol over-the-wire, self-expanding stent available in various stent diameters $(2.5,3.0,3.5,4.0$, and $4.5 \mathrm{~mm})$ and lengths $(9,15$, and $20 \mathrm{~mm})$. The hydrophilic Gateway PTA balloon catheter and silicone balloon come in various diameters and lengths. The manufacturer recommends a submaximal angioplasty to achieve $80 \%$ of normal vessel diameter. The Pharos Vitesse (Micrus Endovascular Corp.) is a cobalt-chromium, open-cell, silicon carbide-coated balloon-expandable stent. Although it is Confirmité Européene (CE) Mark-approved in Europe, it is currently limited as an investigational device in the US.

The Stenting and Aggressive Medical Therapy for Preventing Recurrent Stroke in Intracranial Stenosis (SAMMPRIS) was the first multicenter, prospective, randomized controlled trial comparing angioplasty and stenting plus best medical therapy versus best medical therapy alone in patients with severe $(70 \%-99 \%)$ symptomatic stenosis of a major intracranial artery. This study involved the only FDA-approved devices, the Gateway angioplasty balloon and the Wingspan stent. Best medical therapy included dual antiplatelet therapy with aspirin and clopidogrel, and blood pressure and cholesterol control. The study was stopped early after only 451 of the planned 764 patients had been enrolled because of futility analysis. Patients who underwent endovascular treatment had a significantly higher risk of 30-day stroke and death (14.7\%) compared with patients who received best medical therapy alone (5.8\%). This finding led the FDA to narrow the indications for use of the Wingspan stent to patients who had at least 2 recurrent strokes despite best medical therapy with dual antiplatelet medications and risk factor modification. Fur- ther trials are currently underway to evaluate the efficacy of the Wingspan stent within these narrowed indications.

Similarly, the Vitesse Intracranial Stent Study for Ischemic Stroke Therapy (VISSIT) trial, a separate multicenter, prospective, randomized controlled trial, evaluated the Pharos Vitesse balloon-expandable stent with best medical therapy versus medical therapy alone in the same high-risk patient population..$^{70}$ Again, this study was stopped early after just 112 of the planned 250 patients were enrolled because early interim analysis, in response to the SAMMPRIS results, showed higher risk in the endovascular treatment arm. Patients who underwent endovascular treatment had a higher risk of stroke or death within the first 30 days $(24.1 \%)$ than patients who received medical therapy alone $(9.4 \%)$.

Studies to date have failed to demonstrate the efficacy of intracranial stenting in preventing future strokes in patients with intracranial atherosclerotic disease as compared with best medical management. The SAMMPRIS trial did demonstrate the effectiveness of dual antiplatelet medications, as well as aggressive lifestyle modification and risk factor management with antihypertensive medication and statin therapy; patient outcomes in the medical arm were better than expected based on results from the WASID trial. As was the case with CAS, intracranial stenting may ultimately prove to be effective, but likely only after further technique and device refinement and better patient selection.

\section{Cutting and Drug-Eluting Balloon Angioplasty}

Many of the technical advances with balloon angioplasty are derived from the cardiology literature, where cutting balloons and drug-eluting balloons (DEBs) have been used for treating ISR as well as de-novo small vessel disease of coronary arteries. ${ }^{48}$ The cutting balloon was designed with sharp blades to create regular longitudinal surgical cuts from the luminal surface and into the medial layer in an attempt to limit irregular intimal injury and elastic recoil. ${ }^{3}$ Likewise, the successful use of cutting balloons has been described for the treatment of carotid artery restenosis, with safety and durability. ${ }^{6,64}$ However, there is not yet consensus on specific management strategies for carotid ISR, with options including repeat angioplasty, repeat stent placement, and CEA with stent removal. ${ }^{67}$

Drug-eluting balloons are covered in paclitaxel or oth- 

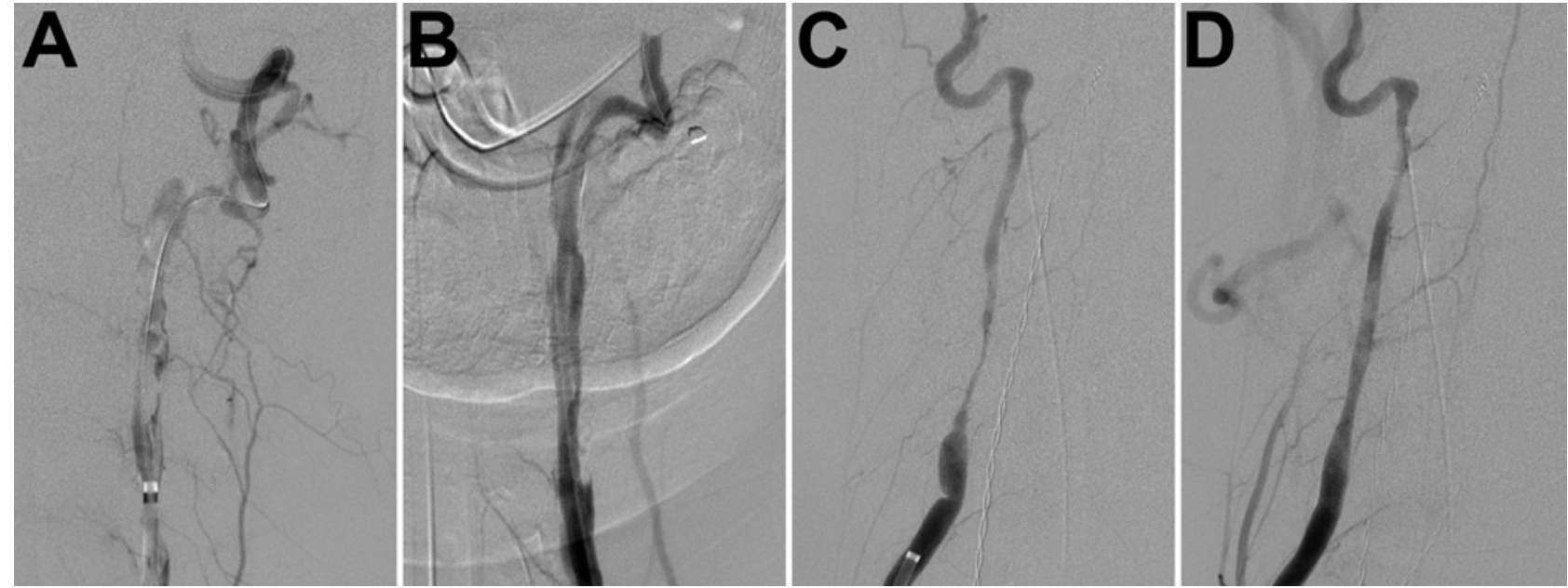

FIG. 4. A and B: Angiograms from a 35-year-old woman who was involved in a motor vehicle accident and had bilateral (A, left, and $B$, right) vertebral artery dissections. $C$ and D: Two $4 \times 30-$ mm PEDs were deployed over the area of dissection, which resulted in increased luminal flow through the PEDs.

er antiproliferative agents such as sirolimus or zotarolimus. These balloons are kept inflated for 30-60 seconds to allow adequate transfer of the antiproliferative agent. Although initially developed and described for coronary arteries, DEB angioplasty has also been employed for treatment of ISR of the carotid artery. ${ }^{42,45}$ It has also been described as an adjunct treatment prior to CAS in patients with restenosis after CEA. ${ }^{56}$ One study that described DEB angioplasty for the treatment of patients with severe refractory ISR after multiple endovascular interventions demonstrated that the treatment was durable in 6 of 9 patients; in the 3 patients who developed recurrent ISR, the time to restenosis was significantly longer than after previous interventions. ${ }^{30}$

Another promising application of balloon angioplasty is for the treatment of intracranial stenosis, especially in light of the disappointing results from the SAMMPRIS trial. Restenosis risk in coronary arteries is significantly higher in smaller caliber vessels; ${ }^{7}$ thus, a treatment strategy that does not involve a permanent stent with risk of late ISR and further luminal caliber decrease may be superior. A study of 41 consecutive patients with atherosclerotic stenosis of intracranial vessels treated with submaximal angioplasty alone showed a 30-day event rate of $4.9 \%$ and a 1-year perioperative and ischemic event-free survival rate of $91 \%$, both of which were better than either the medical or stenting arm of the SAMMPRIS trial. ${ }^{24}$ A follow-up Phase I trial showed even better safety results with no 30day ischemic events, and only 1 patient who had recurrent stroke at 1 year (5.55\%). ${ }^{25}$ Additionally, the Balloon Elution and Late Loss Optimization (BELLO) trial showed that DEB angioplasty may be superior to drug-eluting stenting for small-caliber coronary vessels. ${ }^{39,49}$

\section{Future Directions \\ Drug-Eluting Stents}

The history of the development of cardiac stents has provided a vast fund of experience from which to draw.
Early BMSs were a step forward from balloon angioplasty but had high rates of in-stent thrombosis. This would often pose life-threatening complications, and revascularization was needed in as many as $20 \%$ of patients shortly after treatment. ${ }^{60}$ Several solutions were attempted, including local and systemic administration of various agents to help delay or prevent in-stent thrombosis. ${ }^{21}$ Eventually, some of these agents were incorporated as DESs with promising initial results. Paclitaxel- or sirolimus-eluting stents were the first to be developed and demonstrated improved revascularization and reduced rates of in-stent thrombosis when compared with BMSs. ${ }^{23,63}$ Both of these agents work by an antiproliferative mechanism that prevents the migration and proliferation of endothelial smooth muscle cells, thus reducing rates of neointimal hyperplasia..$^{18}$ DESs have proven their efficacy in preventing in-stent thrombosis compared with BMSs in the short term, but late stent thrombosis continues to be a problem..$^{22,65}$ Some of these late stent failures were attributed to stent material design; as a result, second-generation DESs were introduced using more biocompatible materials. ${ }^{38}$ Although secondgenerations DESs demonstrated decreased rates of late in-stent thrombosis, this complication continues to occur in as many as $1.3 \%$ of patients, an important limitation to consider if these devices are to be used for the treatment of intracranial disease. ${ }^{29}$

\section{Flow-Diverting Stents}

A new class of endovascular devices that could play an important role in the treatment of ischemic stroke is the flow diverter, a stentlike device that redirects the flow of blood through the parent vessel. The Pipeline Embolization Device (PED; Covidien) is the only flow diverter approved in the US for the treatment of intracranial aneurysms; it has several important characteristics that make it a suitable candidate for such use (Fig. 4). First, the stent provides a scaffold to promote endothelial proliferation across the diseased vascular segment..$^{50}$ Second, its ability 
to maintain the patency of critical perforators along both the internal carotid artery and vertebral artery make it an ideal candidate for use..$^{40,44,50}$ Although there are no off-label reports of its use primarily for atherosclerotic disease, 1 report of its use as salvage therapy for a complication during angioplasty in a patient with severe atherosclerotic disease demonstrates its potential use for this purpose. ${ }^{68}$

As in the case of cardiac stents, stent thrombosis remains a continual challenge. Although long-term reports are limited, stenosis rates of $10 \%$ after a median of 6 months were reported in 1 series, although there were no adverse neurological outcomes. ${ }^{36}$ To mitigate this complication, a new coating technology of phosphorylcholine termed "Shield Technology" (Medtronic) has recently been developed and is in the early phases of testing, with clinical trials recruiting in Australia and Spain. Phosphorylcholine is an integral component of red blood cell membranes and has demonstrated resistance to platelet adhesion and intimal hyperplasia. ${ }^{12,14}$ Early animal studies have shown that a coating of phosphorylcholine reduced thrombogenicity of deployed PEDs with and without the use of adjuvant dual antiplatelet therapy. ${ }^{32}$ Additionally, this coating could potentially be used on existing stents already in use for intracranial disease.

\section{Absorbable Stents}

Although second-generation coronary DESs have been shown to have better clinical outcomes than BMSs or firstgeneration DESs, there are still concerns regarding longterm adverse events secondary to neoatherosclerosis and stent fracture.$^{54}$ In response to these concerns, bioresorbable vascular scaffolds (BVSs) have been developed that provide structural mechanical support and drug elution for a period of time, after which they are completely resorbed. The Absorb BVS (Abbott Vascular) consists of a $150-\mu \mathrm{m}$-thick poly-L-lactide scaffold with a $7-\mu \mathrm{m}$-thick poly-D,L-lactide coating that elutes everolimus. It has been extensively studied in the cardiac literature and is the only FDA-approved device of its kind for the treatment of coronary artery disease.

A large multicenter prospective randomized trial compared the Absorb BVS with the Xience DES in a noninferiority trial of 2008 patients. ${ }^{28}$ The primary outcome of target-lesion failure occurred in $7.8 \%$ of patients in the Absorb group compared with $6.1 \%$ in the Xience group at 1 year $(p=0.16)$, with nonsignificant differences in the rates of cardiac death, myocardial infarction, or ischemiadriven target-lesion revascularization. The rate of device thrombosis within 1 year was $1.5 \%$ in the Absorb group compared with $0.7 \%$ in the Xience group $(\mathrm{p}=0.13)$. Concerns regarding this study include the fact that it may be underpowered to detect differences in low-frequency events, such as device thrombosis, as well as the relatively short follow-up duration.

Cassese and colleagues ${ }^{13}$ published a large meta-analysis of 6 randomized clinical trials comprising data from 3738 patients randomized to receive percutaneous coronary intervention with either BVSs or second-generation DESs. Although the groups had similar risks of target lesion revascularization, target lesion failure, myocardial infarction, and death, the BVS group had double the risk of definite or probable stent thrombosis $(1.3 \%$ vs $0.5 \%, \mathrm{p}=$ 0.05 ), with the highest risk within 30 days of implantation. This could be due to the fact that the polymer construction is inherently weaker than metal, requiring thicker bulky struts to improve tensile strength that still only provide about half the maximum radial strength of metallic DES. ${ }^{53}$ In response to this, biodegradable metallic stents that have the tensile strength of metal while being fully bioabsorbable, such as zinc and magnesium alloys, are being investigated..$^{10}$

These developments in cardiac BVS are likely to make their way into the neurosurgical literature, as secondgeneration DESs are already being used for the treatment of vertebral artery disease. With further refinement, this technology may be incorporated into stents designed for the intracranial circulation, in which long-term in-stent thrombosis poses a significant risk and traditional metal stents have already been shown to be inferior to best medical therapy. ${ }^{15}$

\section{Biological Stents}

Another approach to addressing the problem of late stent thrombosis is by improving the endothelialization of the implant and avoiding the elution of drugs that may inhibit neointimal tissue growth and delayed arterial healing in current DESs. The cobalt-chromium Genous stent (OrbusNeich) attempts to achieve accelerated endothelialization with a polysaccharide matrix coat containing anti-CD34-positive antibodies that attracts circulating endothelial progenitor cells. A single-center randomized prospective pilot study compared the Genous stent with the Taxus Liberté stent (Boston Scientific), a paclitaxel DES, in 193 patients with a high risk of restenosis. ${ }^{5}$ The Genous group had no cases of stent thrombosis whereas the Taxus group had 5 cases. The Genous group also had fewer episodes of target lesion revascularization (2.0\% vs $5.3 \%)$.

Since that study, OrbusNeich has developed the Combo Dual Therapy stent, which combines anti-CD34-positive coating on the luminal surface with sirolimus drug elution on the abluminal surface. This would theoretically combine benefits of both types of therapy and recently received CE marking in Europe. Neither the Genous nor the Combo stent is available in the US. Currently, there are no prospective comparative studies evaluating the Combo stent.

Alternative biological coatings have been investigated in many other preclinical studies. Heparin and Type IV collagen used together were shown to enhance endothelialization on a titanium surface. ${ }^{71}$ Anti-CD34-positive antibodies combined with vascular endothelial growth factor to coat stainless-steel sheets were found to attract endothelial progenitor cells and promote differentiation. ${ }^{62}$ One group has proposed using oligonucleotides to promote surface endothelialization on cobalt-chromium stents, ${ }^{4}$ and another group proposed seeding nitinol stents with autologous endothelial cells on the stent surface. ${ }^{35}$

Gene-eluting stents have become the subject of basic science and preclinical research. Several genes, such as nitric oxide synthase, vascular endothelial growth factors, and tissue inhibitor of metalloproteinases-3, have been proposed to promote endothelialization and reduce neo- 
intima formation; ${ }^{52}$ however, there is currently no clinical applicability because a suitable vector for gene delivery has yet to be developed. Additionally, the genes may be inactivated during sterilization procedures.

Stem cells are another subject of investigation for stent biocompatibility and tissue healing. One group proposed a nanofiber stent sleeve to prevent stem cells from being washed out and to protect the cells against host immune responses while allowing the stem cells to respond to local environmental factors and release paracrine factors. ${ }^{34}$ The investigators have proposed that the paracrine factors will then activate host cells and intrinsic repair mechanisms.

\section{Systemic Therapy to Prevent Restenosis}

In addition to local drug therapy to prevent IRS, systemic drug therapy with glucose- and lipid-lowering agents has shown promise. Indeed, patients with diabetes have a 2.5 -fold higher risk of restenosis after percutaneous coronary intervention. ${ }^{1}$ The exact mechanisms of restenosis are unclear but are believed to include inflammatory mediators, prothrombotic states, cytokines, adhesion molecules, and advanced glycosylation end products, the same mechanisms that are elevated in diabetes and dyslipidemia. ${ }^{41,57}$ Thiazolidinediones (TZDs) are peroxisome proliferator-activated receptor- $\gamma$ agonists and are commonly used as insulin sensitizers in diabetic individuals. These drugs have been found to inhibit smooth muscle cell growth and migration ${ }^{20}$ and to limit the production of proinflammatory cytokines. ${ }^{61}$ A meta-analysis of randomized controlled trials showed that TZD therapy significantly reduced the risk of ISR after percutaneous coronary intervention in both diabetic (relative risk 0.37, $\mathrm{p}<0.0001$ ) and nondiabetic patients (relative risk $0.16, p=0.0006$ ). ${ }^{31}$

Similarly, dyslipidemia is a major risk factor for atherosclerotic disease, and several clinical trials have shown that statins reduce the risk of coronary events. These drugs are promising agents for preventing ISR as they have been shown to have antiinflammatory and antithrombotic effects and inhibit proliferation and migration of vascular smooth muscle cells. ${ }^{57}$ A post hoc analysis of the Treating to New Targets (TNT) study evaluated the efficacy of low- versus high-dose atorvastatin in 5407 patients with previous percutaneous coronary intervention and their rates of cardiac events and repeat revascularization. ${ }^{37} \mathrm{~Pa}-$ tients receiving high-dose atorvastatin had significantly lower rates of repeat revascularization $(17.3 \%$ vs $22.9 \%$, $\mathrm{p}<0.0001)$.

Systemic drug therapy, including TZDs and statins, has shown promise in the cardiac literature with regard to reducing the risk of cardiac events and revascularization. It is reasonable that the same mechanisms that contribute to cardiac events and ISR in coronary stents that are ameliorated by TZDs and statins may also contribute to strokes and ISR in stents placed in the cerebral vasculature. However, clear prospective randomized trials evaluating the efficacy of these systemic drug therapies are lacking in the neurosurgical literature.

\section{Conclusions}

As a result of ongoing stent development, improvement of endovascular techniques, and prospective clinical trials, CAS has become widely accepted as a safe and effective alternative to CEA in specific groups of patients. Although the same cannot be said about stenting of intracranial or vertebral arteries, we believe that with the same persistence, intracranial and vertebral artery stents will also find acceptance, ultimately with improvement in the outcomes of select groups of patients. Endovascular technologies are constantly evolving, with industry investing heavily in the development of new technologies as well as in the trials to demonstrate their safety and efficacy. A thorough understanding of these trials, as well as the strengths and weaknesses of each endovascular device, will be critical to providing the best individualized care for each patient.

\section{References}

1. Airoldi F, Briguori C, Iakovou I, Stankovic G, Biondi-Zoccai G, Carlino M, et al: Comparison of sirolimus versus paclitaxel eluting stents for treatment of coronary in-stent restenosis. Am J Cardiol 97:1182-1187, 2006

2. Alfonso F, Fernandez C: Second-generation drug-eluting stents. Moving the field forward. J Am Coll Cardiol 58:2629, 2011

3. Barath P, Fishbein MC, Vari S, Forrester JS: Cutting balloon: a novel approach to percutaneous angioplasty. Am J Cardiol 68:1249-1252, 1991

4. Barsotti MC, Al Kayal T, Tedeschi L, Dinucci D, Losi P, Sbrana S, et al: Oligonucleotide biofunctionalization enhances endothelial progenitor cell adhesion on cobalt/chromium stents. J Biomed Mater Res A 103:3284-3292, 2015

5. Beijk MA, Klomp M, van Geloven N, Koch KT, Henriques JP, Baan J, et al: Two-year follow-up of the Genous ${ }^{\mathrm{TM}}$ endothelial progenitor cell capturing stent versus the Taxus Liberté stent in patients with de novo coronary artery lesions with a high-risk of restenosis: a randomized, single-center, pilot study. Catheter Cardiovasc Interv 78:189-195, 2011

6. Bendok BR, Roubin GS, Katzen BT, Boulos AS, Levy EI, Limpijankit T, et al: Cutting balloon to treat carotid in-stent stenosis: technical note. J Invasive Cardiol 15:227-232, 2003

7. Biondi-Zoccai G, Moretti C, Abbate A, Sheiban I: Percutaneous coronary intervention for small vessel coronary artery disease. Cardiovasc Revasc Med 11:189-198, 2010

8. Bonati LH, Dobson J, Featherstone RL, Ederle J, van der Worp HB, de Borst GJ, et al: Long-term outcomes after stenting versus endarterectomy for treatment of symptomatic carotid stenosis: the International Carotid Stenting Study (ICSS) randomised trial. Lancet 385:529-538, 2015

9. Borhani Haghighi A, Edgell RC, Cruz-Flores S, Zaidat OO: Vertebral artery origin stenosis and its treatment. J Stroke Cerebrovasc Dis 20:369-376, 2011

10. Bowen PK, Shearier ER, Zhao S, Guillory RJ II, Zhao F, Goldman J, et al: Biodegradable metals for cardiovascular stents: from clinical concerns to recent $\mathrm{Zn}$-alloys. Adv Healthc Mater 5:1121-1140, 2016

11. Brott TG, Hobson RW II, Howard G, Roubin GS, Clark WM, Brooks W, et al: Stenting versus endarterectomy for treatment of carotid-artery stenosis. N Engl J Med 363:11-23, 2010

12. Campbell EJ, O'Byrne V, Stratford PW, Quirk I, Vick TA, Wiles MC, et al: Biocompatible surfaces using methacryloylphosphorylcholine laurylmethacrylate copolymer. ASAIO J 40:M853-M857, 1994

13. Cassese S, Byrne RA, Ndrepepa G, Kufner S, Wiebe J, Repp $\mathrm{J}$, et al: Everolimus-eluting bioresorbable vascular scaffolds versus everolimus-eluting metallic stents: a meta-analysis of randomised controlled trials. Lancet 387:537-544, 2016 
14. Chen C, Lumsden AB, Ofenloch JC, Noe B, Campbell EJ, Stratford PW, et al: Phosphorylcholine coating of ePTFE grafts reduces neointimal hyperplasia in canine model. Ann Vasc Surg 11:74-79, 1997

15. Chimowitz MI, Lynn MJ, Derdeyn CP, Turan TN, Fiorella D, Lane BF, et al: Stenting versus aggressive medical therapy for intracranial arterial stenosis. N Engl J Med 365:993-1003, 2011

16. Chimowitz MI, Lynn MJ, Howlett-Smith H, Stern BJ, Hertzberg VS, Frankel MR, et al: Comparison of warfarin and aspirin for symptomatic intracranial arterial stenosis. N Engl J Med 352:1305-1316, 2005

17. Compter A, van der Worp HB, Schonewille WJ, Vos JA, Boiten J, Nederkoorn PJ, et al: Stenting versus medical treatment in patients with symptomatic vertebral artery stenosis: a randomised open-label phase 2 trial. Lancet Neurol 14:606614, 2015

18. Costa MA, Simon DI: Molecular basis of restenosis and drug-eluting stents. Circulation 111:2257-2273, 2005

19. Coward LJ, McCabe DJ, Ederle J, Featherstone RL, Clifton A, Brown MM: Long-term outcome after angioplasty and stenting for symptomatic vertebral artery stenosis compared with medical treatment in the Carotid And Vertebral Artery Transluminal Angioplasty Study (CAVATAS): a randomized trial. Stroke 38:1526-1530, 2007

20. de Dios ST, Bruemmer D, Dilley RJ, Ivey ME, Jennings GL, Law RE, et al: Inhibitory activity of clinical thiazolidinedione peroxisome proliferator activating receptor-gamma ligands toward internal mammary artery, radial artery, and saphenous vein smooth muscle cell proliferation. Circulation 107:2548-2550, 2003

21. de Feyter PJ, Vos J, Rensing BJ: Anti-restenosis trials. Curr Interv Cardiol Rep 2:326-331, 2000

22. De Luca G, Dirksen MT, Spaulding C, Kelbaek H, Schalij M, Thuesen L, et al: Drug-eluting vs bare-metal stents in primary angioplasty: a pooled patient-level meta-analysis of randomized trials. Arch Intern Med 172:611-622, 2012

23. Di Lorenzo E, Sauro R, Varricchio A, Capasso M, Lanzillo $\mathrm{T}$, Manganelli F, et al: Benefits of drug-eluting stents as compared to bare metal stent in ST-segment elevation myocardial infarction: four year results of the PaclitAxel or SirolimusEluting stent vs bare metal stent in primary angiOplasty (PASEO) randomized trial. Am Heart J 158:e43-e50, 2009

24. Dumont TM, Kan P, Snyder KV, Hopkins LN, Siddiqui AH, Levy EI: Revisiting angioplasty without stenting for symptomatic intracranial atherosclerotic stenosis after the stenting and aggressive medical management for preventing recurrent stroke in intracranial stenosis (SAMMPRIS) study. Neurosurgery 71:1103-1110, 2012

25. Dumont TM, Sonig A, Mokin M, Eller JL, Sorkin GC, Snyder KV, et al: Submaximal angioplasty for symptomatic intracranial atherosclerosis: a prospective Phase I study. J Neurosurg 125:964-971, 2016

26. Ederle J, Bonati LH, Dobson J, Featherstone RL, Gaines PA, Beard JD, et al: Endovascular treatment with angioplasty or stenting versus endarterectomy in patients with carotid artery stenosis in the Carotid and Vertebral Artery Transluminal Angioplasty Study (CAVATAS): long-term follow-up of a randomised trial. Lancet Neurol 8:898-907, 2009

27. Eisenberg MJ, Richard PR, Libersan D, Filion KB: Safety of short-term discontinuation of antiplatelet therapy in patients with drug-eluting stents. Circulation 119:1634-1642, 2009

28. Ellis SG, Kereiakes DJ, Metzger DC, Caputo RP, Rizik DG, Teirstein PS, et al: Everolimus-eluting bioresorbable scaffolds for coronary artery disease. N Engl J Med 373:1905-1915, 2015

29. Finn AV, Joner M, Nakazawa G, Kolodgie F, Newell J, John $\mathrm{MC}$, et al: Pathological correlates of late drug-eluting stent thrombosis: strut coverage as a marker of endothelialization. Circulation 115:2435-2441, 2007
30. Gandini R, Del Giudice C, Da Ros V, Sallustio F, Altobelli S, D'Onofrio A, et al: Long-term results of drug-eluting balloon angioplasty for treatment of refractory recurrent carotid instent restenosis. J Endovasc Ther 21:671-677, 2014

31. Geng DF, Jin DM, Wu W, Wang Z, Wang JF: Effect of thiazolidinediones on in-stent restenosis in patients after coronary stenting: a meta-analysis of randomized controlled trials. Atherosclerosis 202:521-528, 2009

32. Hagen MW, Girdhar G, Wainwright J, Hinds MT: Thrombogenicity of flow diverters in an ex vivo shunt model: effect of phosphorylcholine surface modification. J Neurointerv Surg [epub ahead of print], 2016

33. Hughes S: VIST: Vertebral artery stenting may reduce recurrent stroke. Medscape. May 30, 2016 (http://www.medscape. com/viewarticle/863997) [Accessed February 14, 2017]

34. Hwang CW, Johnston PV, Gerstenblith G, Weiss RG, Tomaselli GF, Bogdan VE, et al: Stem cell impregnated nanofiber stent sleeve for on-stent production and intravascular delivery of paracrine factors. Biomaterials 52:318-326, 2015

35. Jantzen AE, Noviani M, Mills JS, Baker KM, Lin FH, Truskey GA, et al: Point-of-care seeding of nitinol stents with blood-derived endothelial cells. J Biomed Mater Res B Appl Biomater 104:1658-1665, 2016

36. John S, Bain MD, Hui FK, Hussain MS, Masaryk TJ, Rasmussen PA, et al: Long-term follow-up of in-stent stenosis after Pipeline flow diversion treatment of intracranial aneurysms. Neurosurgery 78:862-867, 2016

37. Johnson C, Waters DD, DeMicco DA, Breazna A, Bittner $\mathrm{V}$, Greten $\mathrm{H}$, et al: Comparison of effectiveness of atorvastatin $10 \mathrm{mg}$ versus $80 \mathrm{mg}$ in reducing major cardiovascular events and repeat revascularization in patients with previous percutaneous coronary intervention (post hoc analysis of the Treating to New Targets [TNT] Study). Am J Cardiol 102:1312-1317, 2008

38. Kuramitsu S, Shirai S, Ando K: Mechanism of in-stent restenosis after second-generation drug-eluting stents (DES): is it different from bare-metal stents and first-generation DES? J Thorac Dis 7:E599-E602, 2015

39. Latib A, Colombo A, Castriota F, Micari A, Cremonesi A, De Felice F, et al: A randomized multicenter study comparing a paclitaxel drug-eluting balloon with a paclitaxel-eluting stent in small coronary vessels: the BELLO (Balloon Elution and Late Loss Optimization) study. J Am Coll Cardiol 60:24732480, 2012

40. Levitt MR, Park MS, Albuquerque FC, Moon K, Kalani MY, McDougall CG: Posterior inferior cerebellar artery patency after flow-diverting stent treatment. AJNR Am J Neuroradiol 37:487-489, 2016

41. Lexis CP, Rahel BM, Meeder JG, Zijlstra F, van der Horst IC: The role of glucose lowering agents on restenosis after percutaneous coronary intervention in patients with diabetes mellitus. Cardiovasc Diabetol 8:41, 2009

42. Liistro F, Porto I, Grotti S, Ventoruzzo G, Vergallo R, Bellandi G, et al: Drug-eluting balloon angioplasty for carotid in-stent restenosis. J Endovasc Ther 19:729-733, 2012

43. Markus HS, Droste DW, Kaps M, Larrue V, Lees KR, Siebler M, et al: Dual antiplatelet therapy with clopidogrel and aspirin in symptomatic carotid stenosis evaluated using Doppler embolic signal detection: the Clopidogrel and Aspirin for Reduction of Emboli in Symptomatic Carotid Stenosis (CARESS) trial. Circulation 111:2233-2240, 2005

44. Mazur MD, Kilburg C, Wang V, Taussky P: Pipeline embolization device for the treatment of vertebral artery aneurysms: the fate of covered branch vessels. J Neurointerv Surg 8:1041-1047, 2016

45. Montorsi P, Galli S, Ravagnani PM, Trabattoni D, Fabbiocchi F, Lualdi A, et al: Drug-eluting balloon for treatment of in-stent restenosis after carotid artery stenting: preliminary report. J Endovasc Ther 19:734-742, 2012

46. Moufarrij NA, Little JR, Furlan AJ, Williams G, Marzewski 
DJ: Vertebral artery stenosis: long-term follow-up. Stroke 15:260-263, 1984

47. Mozaffarian D, Benjamin EJ, Go AS, Arnett DK, Blaha MJ, Cushman M, et al: Heart Disease and Stroke Statistics-2016 Update: a report from the American Heart Association. Circulation 133:e38-e360, 2016 (Erratum in Circulation 133:e599, 2016)

48. Muramatsu T, Tsukahara R, Ho M, Ito Y, Hirano K, Ishimori $\mathrm{H}$, et al: Efficacy of cutting balloon angioplasty for in-stent restenosis: an intravascular ultrasound evaluation. J Invasive Cardiol 13:439-444, 2001

49. Naganuma T, Latib A, Sgueglia GA, Menozzi A, Castriota F, Micari A, et al: A 2-year follow-up of a randomized multicenter study comparing a paclitaxel drug-eluting balloon with a paclitaxel-eluting stent in small coronary vessels the BELLO study. Int J Cardiol 184:17-21, 2015

50. Nelson PK, Lylyk P, Szikora I, Wetzel SG, Wanke I, Fiorella $D$ : The pipeline embolization device for the intracranial treatment of aneurysms trial. AJNR Am J Neuroradiol 32:34-40, 2011

51. North American Symptomatic Carotid Endarterectomy Trial Collaborators: Beneficial effect of carotid endarterectomy in symptomatic patients with high-grade carotid stenosis. $\mathbf{N}$ Engl J Med 325:445-453, 1991

52. O'Brien B, Zafar H, Ibrahim A, Zafar J, Sharif F: Coronary stent materials and coatings: a technology and performance update. Ann Biomed Eng 44:523-535, 2016

53. Onuma Y, Serruys PW: Bioresorbable scaffold: the advent of a new era in percutaneous coronary and peripheral revascularization? Circulation 123:779-797, 2011

54. Otsuka F, Vorpahl M, Nakano M, Foerst J, Newell JB, Sakakura K, et al: Pathology of second-generation everolimus-eluting stents versus first-generation sirolimus- and paclitaxel-eluting stents in humans. Circulation 129:211-223, 2014

55. Park MS, Fiorella D, Stiefel MF, Dashti SR, Gonzalez LF, McDougall CG, et al: Vertebral artery origin stents revisited: improved results with paclitaxel-eluting stents. Neurosurgery 67:41-48, 2010

56. Piccoli G, Biondi-Zoccai G, Gavrilovic V, Radici V, Cancelli I, Frigatti P, et al: Drug-coated balloon dilation before carotid artery stenting of post-carotid endarterectomy restenosis. $\mathbf{J}$ Endovasc Ther 22:212-216, 2015

57. Prasad K: Do statins have a role in reduction/prevention of post-PCI restenosis? Cardiovasc Ther 31:12-26, 2013

58. Sacco RL, Kargman DE, Gu Q, Zamanillo MC: Race-ethnicity and determinants of intracranial atherosclerotic cerebral infarction. The Northern Manhattan Stroke Study. Stroke 26:14-20, 1995

59. Serruys PW, Kutryk MJ, Ong AT: Coronary-artery stents. N Engl J Med 354:483-495, 2006

60. Serruys PW, Unger F, Sousa JE, Jatene A, Bonnier HJ, Schönberger JP, et al: Comparison of coronary-artery bypass surgery and stenting for the treatment of multivessel disease. N Engl J Med 344:1117-1124, 2001

61. Sidhu JS, Cowan D, Kaski JC: The effects of rosiglitazone, a peroxisome proliferator-activated receptor-gamma agonist, on markers of endothelial cell activation, C-reactive protein, and fibrinogen levels in non-diabetic coronary artery disease patients. J Am Coll Cardiol 42:1757-1763, 2003
62. Song CL, Li Q, Zhang JC, Wang JP, Xue X, Wang G, et al: Study of a novel coating strategy for coronary stents: evaluation of stainless metallic steel coated with VEGF and anti-CD34 antibody in vitro. Eur Rev Med Pharmacol Sci 20:311-316, 2016

63. Stone GW, Lansky AJ, Pocock SJ, Gersh BJ, Dangas G, Wong SC, et al: Paclitaxel-eluting stents versus baremetal stents in acute myocardial infarction. N Engl J Med 360:1946-1959, 2009

64. Tamberella MR, Yadav JS, Bajzer CT, Bhatt DL, Abou-Chebl A: Cutting balloon angioplasty to treat carotid in-stent restenosis. J Invasive Cardiol 16:133-135, 2004

65. Tank VH, Ghosh R, Gupta V, Sheth N, Gordon S, He W, et al: Drug eluting stents versus bare metal stents for the treatment of extracranial vertebral artery disease: a meta-analysis. J Neurointerv Surg 8:770-774, 2016

66. Vajda Z, Miloslavski E, Güthe T, Fischer S, Albes G, Heuschmid A, et al: Treatment of stenoses of vertebral artery origin using short drug-eluting coronary stents: improved follow-up results. AJNR Am J Neuroradiol 30:1653-1656, 2009

67. van Haaften AC, Bots ML, Moll FL, de Borst GJ: Therapeutic options for carotid in-stent restenosis: review of the literature. J Vasc Interv Radiol 21:1471-1477, 2010

68. Velioglu M, Ozturk E, Sonmez G, Kendirli T, Mutlu H, Basekim C: Flow diverter as a rescue therapy for a complicated basilar angioplasty. Diagn Interv Radiol 19:345-348, 2013

69. Yadav JS, Wholey MH, Kuntz RE, Fayad P, Katzen BT, Mishkel GJ, et al: Protected carotid-artery stenting versus endarterectomy in high-risk patients. N Engl J Med 351:1493-1501, 2004

70. Zaidat OO, Fitzsimmons BF, Woodward BK, Wang Z, Killer-Oberpfalzer M, Wakhloo A, et al: Effect of a balloonexpandable intracranial stent vs medical therapy on risk of stroke in patients with symptomatic intracranial stenosis: the VISSIT randomized clinical trial. JAMA 313:1240-1248, 2015

71. Zhang K, Chen JY, Qin W, Li JA, Guan FX, Huang N: Constructing bio-layer of heparin and type IV collagen on titanium surface for improving its endothelialization and blood compatibility. J Mater Sci Mater Med 27:81, 2016

\section{Disclosures}

Dr. Taussky has served as a consultant to Covidien/Medtronic.

\section{Author Contributions}

Conception and design: Park, Yoon. Drafting the article: Yoon, Awad. Critically revising the article: Park, Kalani, Taussky. Reviewed submitted version of manuscript: Park, Yoon, Kalani, Taussky. Approved the final version of the manuscript on behalf of all authors: Park.

\section{Correspondence}

Min S. Park, Department of Neurosurgery, Clinical Neurosciences Center, 175 North Medical Dr. East, Salt Lake City, UT 84132. email: neuropub@hsc.utah.edu. 